\title{
Control of Residual Stress and Distortion in Aluminium Wire + Arc Additive Manufacture with Rolling
}

\author{
J. R. Hönnige, P. A. Colegrove, S. Ganguly, E. Eimer, S. Kabra*, S. Williams \\ Welding Engineering and Laser Processing Centre (WELPC), Cranfield University, Cranfield, Bedfordshire, MK43 OAL, UK \\ *ISIS Facility, Science and Technology Facilities Council, Rutherford Appleton Laboratory, Harwell Oxford, Didcot, Oxfordshire, OX11 \\ OQX, UK
}

\begin{abstract}
Rolling can control residual stress and distortion in aluminium Wire + Arc Additively Manufactured (WAAM) walls. It was applied both vertically to each deposited layer (inter-pass) and to the side of the wall after deposition is completed. Distortion was virtually eliminated with the vertical inter-pass method (unlike other metals) and inverted with side rolling. Neutron diffraction stress measurements show that the deposited wall contains constant tensile residual stresses along the build direction that reach the flow strength of the alloy in longitudinal direction. Vertical interpass rolling eliminates the distortion, but produces a multi-directional stress field, with hydrostatic compressive stresses approximately $2 \mathrm{~mm}$ below the top surface and hydrostatic tension 5-10 mm below the surface. Side rolling was even more effective in stress and distortion control and produced fairly uniform longitudinal compressive stresses along the wall height. An interesting by-product of the neutron diffraction measurements is the observation of a significantly larger FCC aluminium unit cell in the inter-pass rolled walls. This is a result of less copper in solid solution with the aluminium matrix, indicating greater precipitation which could have contributed to the material's improved strength.
\end{abstract}

\section{Introduction}

Wire + arc additive manufacturing (WAAM) is a high-deposition-rate additive manufacturing process, which can be used for the manufacture of large-scale structural parts of medium complexity. Commercial welding torches are manipulated by a robotic or CNC-system to deposit metal wire on a substrate, using welding arcs as a power sources [1]. Metal Inert Gas (MIG), Tungsten Inert Gas (TIG) and plasma power sources can be used to deposit a wide range of metals including steel, Ti-6Al-4V and aluminium alloys [2]-[4]. Alternate additive manufacturing processes are laser [5] and electron beam [6] based systems that deposit metal wire or powder [7], [8]. WAAM techniques provide a high deposition rate at the expense of dimensional resolution and minimum feature size and are typically compared against conventional manufacturing techniques, such as machining, casting and forging fabrication. The comparison is based upon mechanical properties, build tolerance, buy-to-fly ratio, residual stress and distortion. Benefits of WAAM are dominantly the cost savings through reductions in the material required 
and design optimisation [1], [9], as well as significant reductions in lead time. The deposited nearnet-shape part can be finished by machining or forging [10].

During the repetitive deposition process, each layer exceeds the melting point and cools down again. Due to thermal expansion and constrained shrinkage during cooling, the deposited wall develops residual stresses, comparable to those in welding [11]. The geometry, thermal history, temperature-dependent flow strength and thermal properties of the metal determine the magnitude of these residual stresses in WAAM. When depositing steel for example, the longitudinal residual stresses can be as high as the material's tensile yield strength [12], [13]. In Ti-6Al-4V walls the maximum tensile residual stresses are usually less than $70 \%$ of its yield strength [14], [15]. When the part is still clamped and undistorted, the longitudinal tensile residual stress is constant along the height [16]. After unclamping a linear wall, the part bends upwards to balance the internal stress field. The changed stress field shows a linear drop in longitudinal tensile residual stress from the substrate toward the top of the wall [12]-[17]. Even though aluminium is one of the most widely used materials for WAAM and other AM techniques, there were no detailed investigations on the residual stress development available yet. Sun et al. [18] deposited 2319 aluminium wire using WAAM technology, but only measured the stresses near the wall surface using hole drilling. Only Brice et al. [19] used neutron diffraction to measure bulk stresses in electron beam AM using 2319 wire. However, stresses were only determined at or near the interface with the substrate and along the length of the specimen, rather than the height.

A variety of welding-induced residual stress mitigation techniques are available, which can be considered for WAAM [20]. Thermal techniques include stress relieving, scanning path strategy, pre-heating or depositing with trailing heat sink [19], [21]-[23]. Machine Hammer Peening, Ultrasonic Impact Treatment and Global Mechanical Tensioning are other examples for mechanical approaches [24]-[27]. Another promising mechanical technique to manipulate the residual stresses and distortion is cold rolling, which initially has been used on butt welds [28][31], because it can efficiently eliminate residual stresses and distortion. Figure 1 (a) shows the schematic of vertical rolling of butt welds, which strains the weld seam predominantly in the longitudinal direction and hence reduces the residual stresses and distortion. When applied to additive manufacture, as shown in Figure 1 (b), this technique is less effective, because the main direction of plastic deformation is transverse to the deposition direction due to absence of any lateral restraint. Hence vertical rolling only reduces, and does not eliminate residual stress and distortion in steel and Ti-6AI-4V WAAM [12], [32], [33]. Colegrove et al. [12] showed that constraining the transverse deformation can significantly improve the effect of vertical rolling on 
the distortion. Hönnige et al. [14] developed the side rolling technique, illustrated in Figure 1 (c). By applying the load in the transverse direction, the wall is strained in the longitudinal and normal directions, which counteracts the as-deposited residual stresses effectively. Side rolling was able to mitigate residual stresses and eliminates distortion in Ti-6AI-4V WAAM [14]. Although side rolling appears not practical from industrial perspective, it is seen as the first step towards developing a pinch rolling tool, where two horizontally opposed rollers are used to deform the wall, similar to the one used elsewhere [34]. Pinch rolling can be used on curved walls and has the advantage that the applied force is kept within the rolling mechanism, so no large externally applied load is necessary.
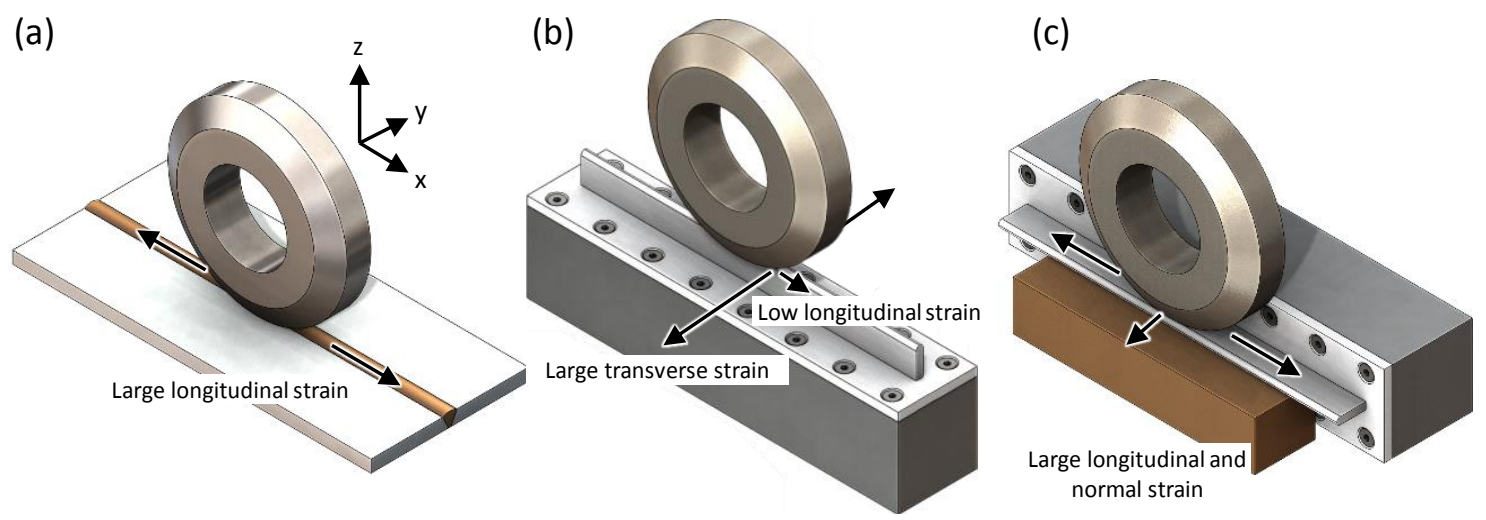

Figure 1: Main directions of strain induced by cold rolling: a) vertical rolling of butt welds; b) vertical rolling of WAAM wall; c) side rolling of WAAM wall

WAAM components, by virtue of the fabrication process, often have anisotropic and inferior mechanical properties compared to their wrought counterparts. This is primarily due to large columnar dendritic grains that grow epitaxially during deposition [35]. However for aluminiumcopper alloys, grain size and solid solution strengthening have a relatively small effect on the mechanical properties when compared to aging or work hardening [36].

WAAM aluminium walls typically contain Al-Cu eutectics ( $\alpha$-Al and $\theta$ phases) which can be $100 \mu \mathrm{m}$ in size. They form during solidification along grain or dendrite boundaries due to the high diffusivity of the liquid melt, which allows copper to concentrate in the remaining liquid so an eutectic composition is the result when solidification is completed [37]. The $\theta$-phase can grow further at elevated temperatures during subsequent depositions but can be re-dissolved by solution treatment [38]. Furthermore the experimentally deposited 2319 WAAM wall contains spherical pores that are typically between 10 and $50 \mu \mathrm{m}$ in diameter that severly reduce tensile and fatigue properties. The as-deposited 2319 material, which contains large precipitates and pores, has a yield strength of $125 \mathrm{MPa}$, which can be increased to over $300 \mathrm{MPa}$ with a T6treatment [39], [40]. Inter-pass rolling has been found not only to modify the internal stresses in WAAM, but also the microstructure [12], [41], [42]. The effect on the aluminium microstructure is grain refinement, a modified morphology of precipitates and the full elimination of porosity, 
which can all be attributed to the increased dislocation density, induced by rolling [39]. With interpass rolling applied on aluminium WAAM, the YS and UTS can be increased by $87 \%$ and $20 \%$ respectively [38].

In this paper the development of residual stresses in 2319 WAAM walls was investigated using neutron diffraction and how vertical inter-pass rolling and side rolling can be used to control residual stress and distortion. The neutron diffraction data furthermore helped to better understand the strengthening mechanism.

\section{Methodology}

A Fronius CMT Advanced 4000R heat source was used to deposit commercial ER2319 wire (1.2 mm diameter) on a $310 \times 65 \times 6.35 \mathrm{~mm}$ 6082-T6 substrate. The nominal chemical composition is shown in Table 1. A six-axis ABB welding robot deposited the $250 \mathrm{~mm}$ long walls layer by layer in alternating direction, using a CMT pulsed advanced wave form with C1369 synergic curve. A wire feed speed of $100 \mathrm{~mm} / \mathrm{s}$ and travel speed of $10 \mathrm{~mm} / \mathrm{s}$ were used with $100 \%$ argon shielding gas at a flow rate of $25 \mathrm{l} / \mathrm{min}$. The contact tip to workpiece distance was $12 \mathrm{~mm}$.

Table 1: Nominal Composition of the ER2319 wire

\begin{tabular}{|c|c|c|c|c|c|c|c|c|c|c|}
\hline & $\mathrm{Al}$ & $\mathrm{Cu}$ & $\mathrm{Mg}$ & $\mathrm{Mn}$ & $\mathrm{Ti}$ & $\mathrm{Zr}$ & Zn & $\mathrm{Si}$ & $\mathrm{Fe}$ & V \\
\hline wt $\%$ & (bal) & $5.8-6.8$ & $\leq 0.02$ & $0.2-0.4$ & $0.1-0.2$ & $0.1-0.25$ & $\leq 0.1$ & $\leq 0.2$ & $\leq 0.3$ & $0.05-0.15$ \\
\hline
\end{tabular}

For the first three layers, the wire feed speed was increased by $33 \%$, which compensated the heat sink effect of the substrate. Rolling was applied with a bespoke gantry based rolling machine, which applied the load with a hydraulic cylinder. The $\mathrm{H} 13$ tool steel rollers used in this study were $20 \mathrm{~mm}$ wide and the diameters were $100 \mathrm{~mm}$ for vertical rolling and $150 \mathrm{~mm}$ for side rolling. This setup, the wire and deposition parameters, as well as the rolling gantry were the same as those described in Gu et al. [38], [39]. Vertical inter-pass rolling was employed between each layer after a $45 \mathrm{~s}$ delay, which allowed the wall to cool down to near room temperature. Loads of $14 \mathrm{kN}$, $28 \mathrm{kN}$ and $42 \mathrm{kN}$ were applied between the layers for comparison with Gu et al. [39] to produce similar contact pressures. For the side rolling trials, the entire wall was built on a portable aluminium backing bar. While the specimen remained clamped to this backing bar, it was rotated by $90^{\circ}$ and side rolled against a $\mathrm{H} 13$ tool steel backing bar, as shown in Figure 1 (c). The postdeposition side rolling loads were $11 \mathrm{kN}, 22 \mathrm{kN}, 44 \mathrm{kN}$ and $66 \mathrm{kN}$. The side rolling setup and wall dimensions were comparable to those in Hönnige et al. [14], who performed the first side rolling trials on a Ti-6AI-4V WAAM wall. The contact during side rolling was along the entire width of the $20 \mathrm{~mm}$ wide roller, while the contact of vertical rolling was limited to the wall width and plastic deformation was limited to the top of the deposit. The applied loads for both rolling processes 
are therefore not comparable, but consistent with the respective references for vertical rolling [39] and side rolling [14]

\subsection{Measurements}

An optical microscope, a calliper and a height gauge were used to determine the cross-sectional wall and layer geometry, as well as the out-of-plane distortion D of the substrate, as shown in Figure 2. Vickers micro hardness testing was carried out along the entire centreline of the cross section from the bottom of the substrate to the top of the wall, as shown in Figure 3 (a). The indents were spaced $0.5 \mathrm{~mm}$ and a load of $200 \mathrm{~g}$ was applied for $15 \mathrm{~s}$.

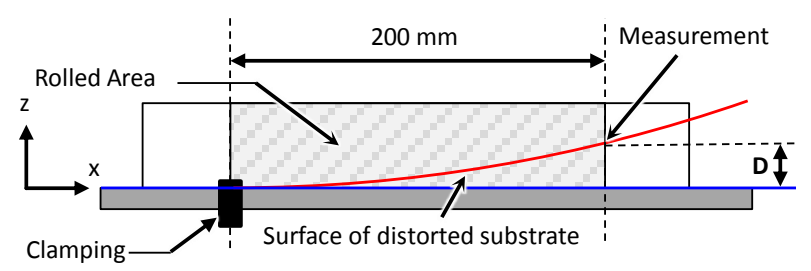

Figure 2: Schematic of the measurement of the out-of-plane distortion $\mathrm{D}$ of the substrate

The residual stress measurements were carried out with the ENGIN-X time-of-flight neutron diffractometer at the ISIS pulsed neutron source of the Rutherford Appleton Laboratory at Harwell [43]. The instrument is optimised to accurately measure lattice spacing of planes in the crystallographic lattice. It does so by using a polychromatic neutron beam, which allows simultaneous refinement of several peaks corresponding to different atomic planes. Changes in plane spacing at different specimen location correspond to strains in these locations. The residual stress calculation was based on this crystallographic lattice strain [43]. Although a polychromatic beam was used, the neutrons are pulsed and the instrument uses the time-of-flight of the arriving neutrons (from source to detector) to determine its energy and consequently the corresponding wavelength. The time-of-flight range was chosen to refine the following four families of crystallographic planes $\{311\},\{220\},\{200\}$ and $\{111\}$ with a nominal $d$-spacing of $d_{311}=1.218 \AA$, $d_{220}=1.428 \AA, d_{200}=2.020 \AA$ and $d_{111}=2.332 \AA$ respectively. All four planes were measured simultaneously, to determine the lattice parameter $a$ by using Pawley refinement [44]. A counting time corresponding to a proton current of $10 \mu \mathrm{A}$ (equivalent to $8 \mathrm{~min}$ per point) was sufficient to achieve a good intensity profile for the eleven $2 \times 2 \times 2 \mathrm{~mm}$ gauge volumes located in the vertical centreline of the specimen and orientated in the 3 orthogonal principal directions. Figure 3 (b) shows the setup for the z-scan during the measurement of the transverse and longitudinal direction. Subsequent rotation around the $y$-axis by $90^{\circ}$ allowed the measurement of the remaining normal direction. Electro discharge machining was deployed to produce stress-free reference samples for each rolling condition to establish the individual unstrained lattice parameter ao. Lattice strain and residual stress have been calculated using eq. (1) and (2), 
$\varepsilon_{i i}=\frac{a_{i}-a_{0}}{a_{0}}$

$\sigma_{x x}=\frac{v E *\left(\varepsilon_{x x}+\varepsilon_{y y}+\varepsilon_{y y}\right)}{(1+v)(1-2 v)}+\frac{E}{1+v} \varepsilon_{x x}$

where $\sigma_{x x}$ is the stress in the global longitudinal direction; $\varepsilon_{i i}$ the measured strain in each orthogonal direction; $E$ and $v$ are the engineering elastic constants ( $E=73.1 \mathrm{GPa} ; \boldsymbol{v}=0.33$ [45]) for 2024 alloy. The error of the residual stress calculation was determined by error propagation of the lattice parameter fitting error during Pawley refinement, which was carried through the strain and then stress calculation [15]. The ENGIN-X instrument has two detectors, which allow the simultaneous measurement of two principal directions. During the measurements of the stress-free $a_{0}$ reference, it was established, that the north detector measured a-values that were on average $2.75 \times 10^{-4} \AA$ smaller than those measured by the south detector. Therefore the strained lattice was always compared against the $a_{0}$ taken from the same orientation using the same detector. This minimises the systematic error and mitigates the potential influence of texture and anisotropy of the stress free lattice, to ensure the measurement of macroscopic stress only.

(a)

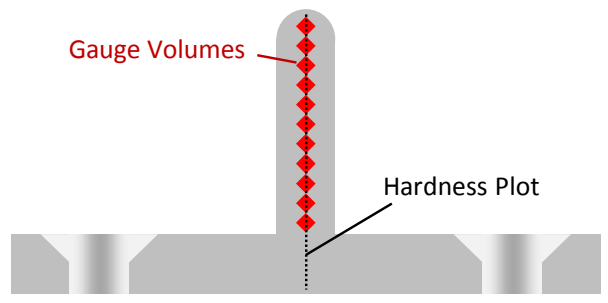

(b)

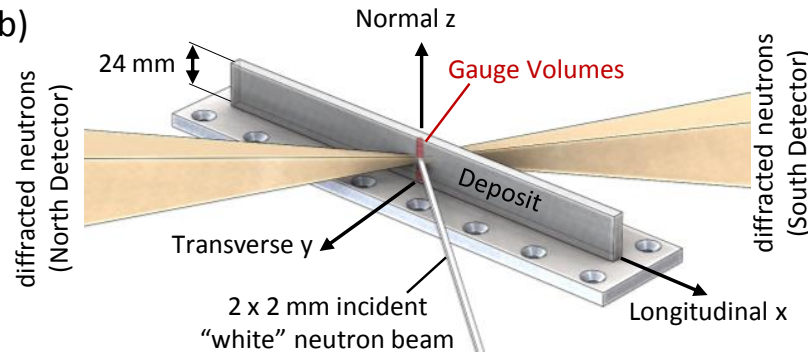

Figure 3: (a) Location of the eleven gauge volumes and hardness plot line in the cross section of the specimen; (b) setup on the ENGIN-X neutron diffraction strain scanner

\section{Results}

\subsection{Geometry}

The control specimen is shown in Figure 4 (a), consisted of 9 layers and was $24.3 \mathrm{~mm}$ high. The effective wall width was $5.5 \mathrm{~mm}$, which is the inside width that contains bulk material and excludes the convex portion of each layer [4]. The effect of vertical inter-pass rolling and side rolling on the geometry and surface condition is shown in Figure $4(b-d)$ and (e-h) respectively. While the surface waviness was increased visibly by vertical rolling, it was smoothened by side rolling. However, as the surface waviness varied along the length and height of the wall, side rolling only resulted in partial contact, especially for lower loads (Figure 4 (e)). Vertical inter-pass rolling reduced the average layer height of $2.7 \mathrm{~mm}$ in the control specimen and increased the effective wall width to the values summarised in Table 2. It shows a significant increase of the wall width to nearly double the control wall in the case of $42 \mathrm{kN}$ rolling load. 


\begin{tabular}{lllll}
\hline & control & $14 \mathrm{kN}$ & $28 \mathrm{kN}$ & $42 \mathrm{kN}$ \\
\hline number of layers & 9 & 10 & 14 & 18 \\
total height [mm] & 24.3 & 23.5 & 23.3 & 24.0 \\
average layer height [mm] & 2.70 & 2.35 & 1.66 & 1.33 \\
effective wall width [mm] & 5.5 & 5.9 & 8.3 & 10.3 \\
vertical strain $\varepsilon_{\mathrm{z}}[\%]$ & - & -13.0 & -38.5 & -50.7 \\
transverse strain $\varepsilon_{\mathrm{y}}[\%]$ & - & +7.3 & +50.9 & +87.3 \\
\hline
\end{tabular}

Since side rolling was performed after the wall was completed, the layer dimensions were comparable to the control specimen prior to rolling. $11 \mathrm{kN}$ and $22 \mathrm{kN}$ side rolling load influenced the surface waviness of the walls, but did not change the total height or effective wall width of the specimen to the accuracy of the measurement. Increasing the load to $44 \mathrm{kN}$ and $66 \mathrm{kN}$ increased the total wall height by $0.5 \mathrm{~mm}\left(\varepsilon_{2} \approx+2.1 \%\right)$ and $0.8 \mathrm{~mm}\left(\varepsilon_{2} \approx+3.3 \%\right)$ respectively and decreased the effective wall width by $0.1 \mathrm{~mm}\left(\varepsilon_{y} \approx-1.8 \%\right)$ and $0.3 \mathrm{~mm}\left(\varepsilon_{y} \approx-5.5 \%\right)$ respectively.

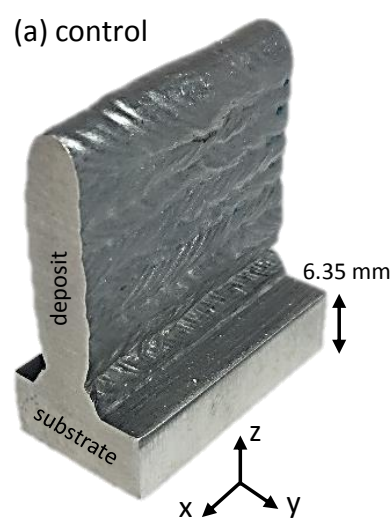

(e) $11 \mathrm{kN}$ side

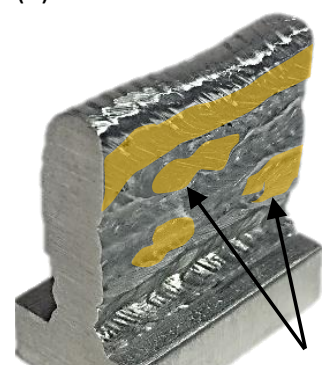

Partial contact

(b) $14 \mathrm{kN}$ vertical

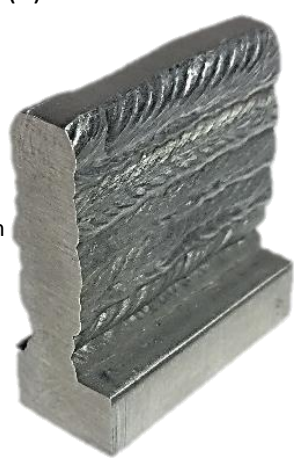

(f) $22 \mathrm{kN}$ side

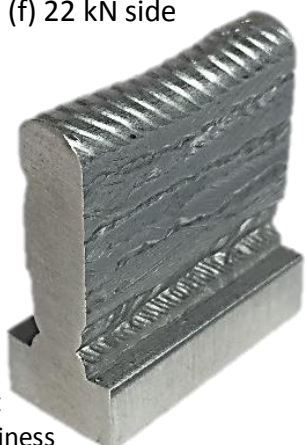

(c) $28 \mathrm{kN}$ vertical

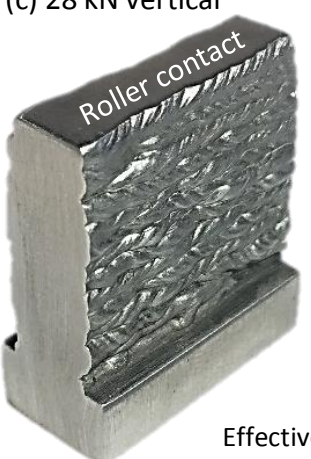

Effective wall width (d) $42 \mathrm{kN}$ vertical

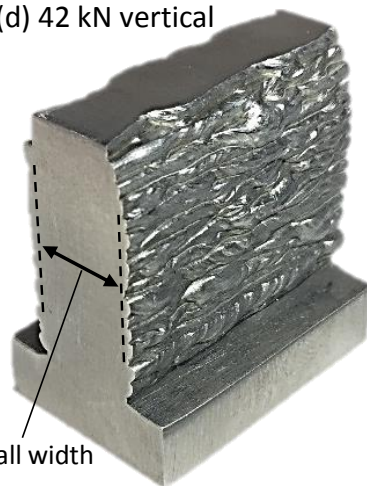

(g) 44 kN side

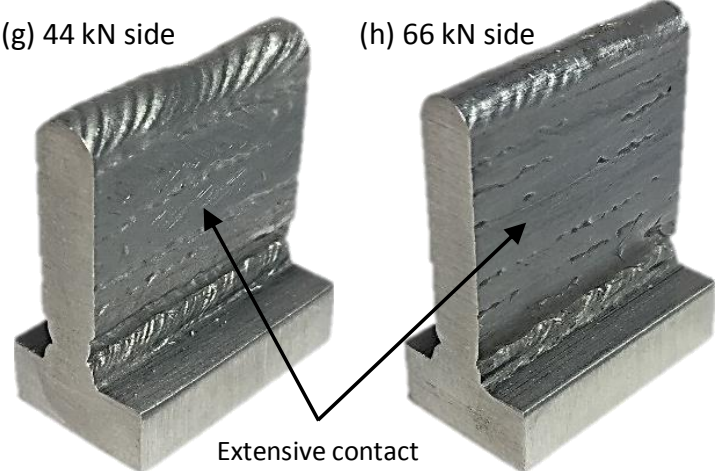

Figure 4: wall shape of (a) the control specimen, (b-d) the vertical inter-pass rolled specimen and (e-h) the side rolled specimen.

Figure 5 (a) shows how vertical inter-pass rolling reduces the distortion to negligible values with increasing load. Side Rolling inverted the distortion as shown in Figure 5 (b). Hence the side rolling process elongated the deposit more than necessary to eliminate the distortion. Since the $11 \mathrm{kN}$ load resulted in random partial contact with the wall due to its' waviness (Figure 4 (e)), a further reduction of the load was therefore not considered reasonable. 
(a)

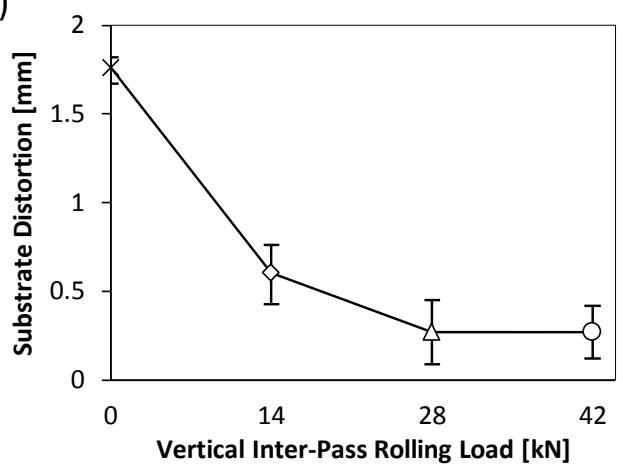

(b)

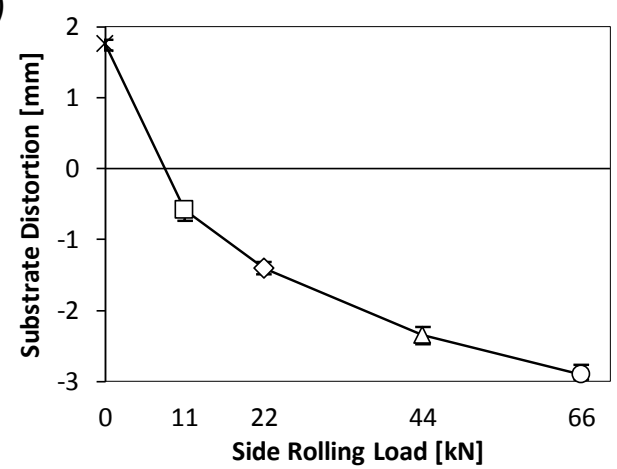

Figure 5: Reduction of out-of-plane distortion D (as per Figure 2) of the control sample by (a) vertical inter-pass rolling and (b) side rolling

\subsection{Hardness}

The results of the micro hardness test of the vertical inter-pass rolled and the side rolled specimens are shown in Figure 6 (a) and (b) respectively. The hardness of the control sample is fairly constant between $75 \mathrm{HV}$ and $85 \mathrm{HV}$ along the wall height, after being slightly higher near the interface with the substrate ( $90 \mathrm{HV}$ ), which has a higher Mg and Si content, due to the 6082 plate used. Up to $18 \mathrm{~mm}$ above the substrate, the sample that has been inter-pass rolled with the $14 \mathrm{kN}$ load shows the same values as the control sample. The $28 \mathrm{kN}$ and $42 \mathrm{kN}$ profiles are approximately $20 \mathrm{HV}$ and $25 \mathrm{HV}$ greater. Above $18 \mathrm{~mm}$ all inter-pass rolled samples show a linear increase in hardness near the top of the wall, reaching a value that is approximately $30 \mathrm{HV}$ higher than the rest of the wall. The side-rolled samples show an increase in hardness, which is rather irregular along the wall height. On average however, the mean hardness increases with increasing rolling load. The $66 \mathrm{kN}$ side rolled sample shows the highest hardness value of $110 \pm 10 \mathrm{HV}$ in the region where the wall has been rolled. 

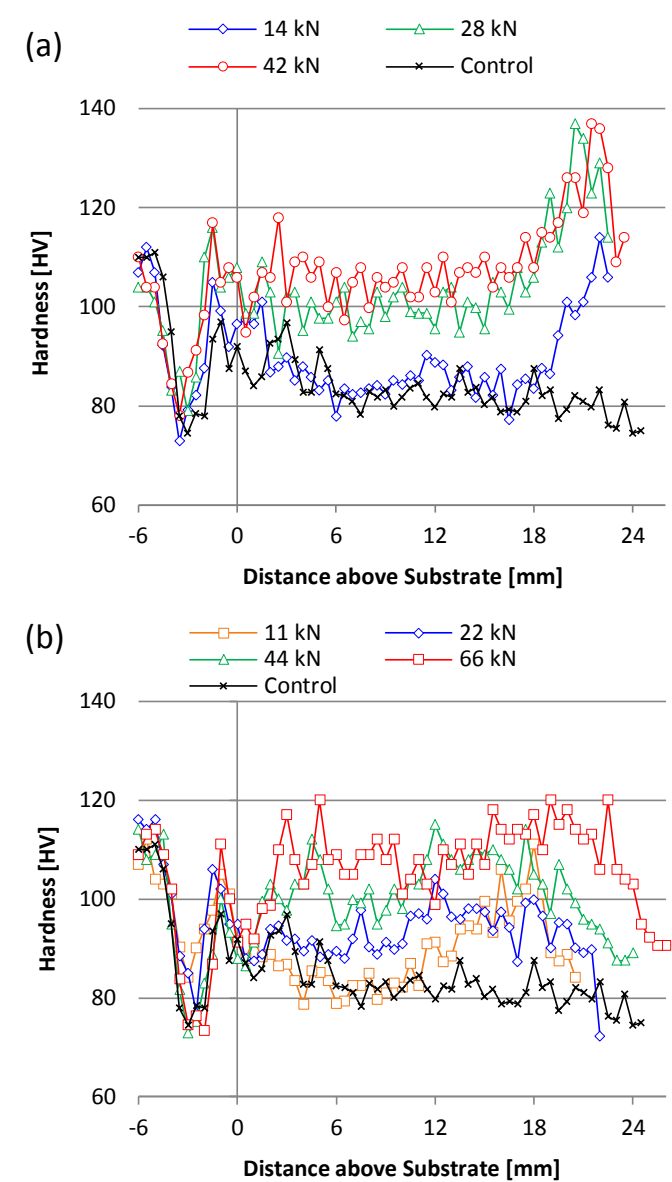

Figure 6: Hardness plots of the (a) vertical inter-pass-rolled walls and (b) side-rolled walls

\subsection{Residual Stress}

A typical diffraction spectrum is shown in Figure $7(a)$, which shows that all the crystallographic planes appear very clear, allowing good accuracy for the fit. The fitting error of the lattice parameter $a_{i}$ was always less than $\pm 2 \times 10^{-4} \AA$, corresponding to less than $50 \times 10^{-6}$ strain. Across the spectrum, several $\mathrm{Al}_{2} \mathrm{Cu} \theta$-peaks could also be identified, based on the tetragonal phase dimensions $a_{\theta}=6.067 \AA$ and $c_{\theta}=4.874 \AA$ [46]. The identified peaks of both phases are indicated in the spectrum.

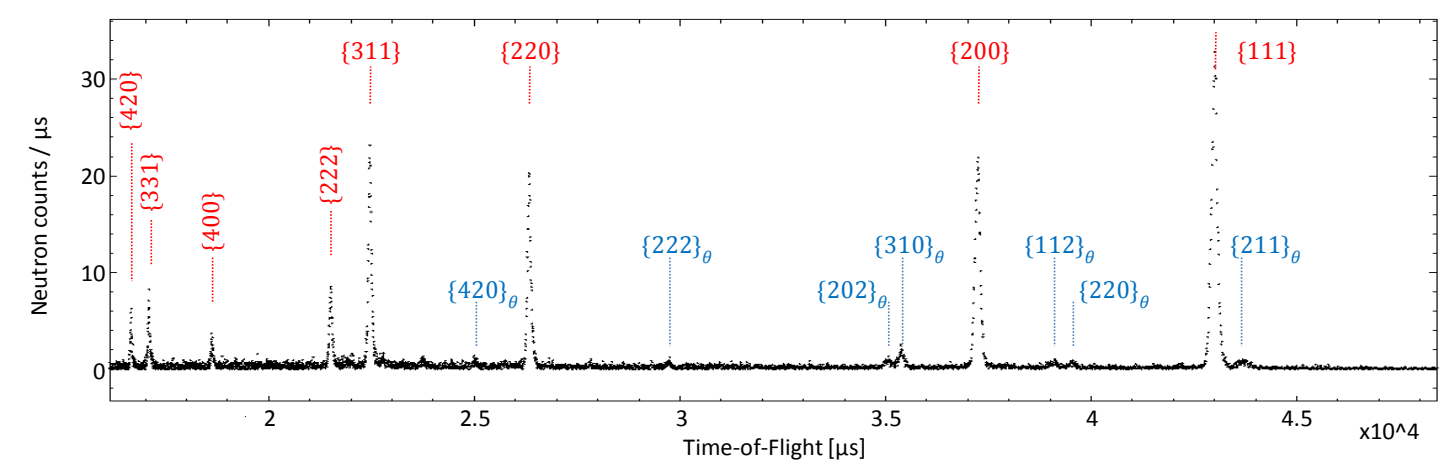

Figure 7: typical time-of-flight spectrum of 2319 WAAM material showing planes of the $\mathrm{Al}$ matrix and $\mathrm{Al}_{2} \mathrm{Cu}-\theta$ phase;

The stress-free lattice parameter $a_{0}$ has been found to be virtually isotropic in each sample. However, between the different rolling treatments, there are considerable variations. The average $a_{0}$ of the as-deposited control specimen and the side-rolled specimen is $4.0427 \AA$. The $a_{0}$ 
of the $14 \mathrm{kN}$ inter-pass rolled sample was $4.0426 \AA$ and is similar in size. The lattice parameters of the $28 \mathrm{kN}$ and $42 \mathrm{kN}$ specimens however were $4.0437 \AA$ and $4.0441 \AA$ respectively, and therefore significantly larger than the other two, as these values represent a pseudo strain of $247 \times 10^{-6}$ and $346 \times 10^{-6}$. The $\theta$ peaks have not been used for stress calculation, but this phase can contain compressive stress, because the thermal expansion of this tetragonal phase is anisotropic: In the normal c-direction of the tetragonal unit cell the expansion is comparable to aluminium, while the expansion of its' basal a-directions are significantly lower. This can result in thermally induced interphase stresses [47], which is beyond the scope of the present data analysis. However, a relatively large gauge volume compared to the specimen can compensate this, which allows representative macrostrain measurements. Table 3 shows that the identified peaks agree exceptionally well with values calculated from the unit cell dimensions from Bradley and Jones [46], using eq. (3),

$\frac{1}{d^{2}}=\frac{h^{2}+k^{2}}{a^{2}}+\frac{l^{2}}{c^{2}}$

where $\mathrm{h}, \mathrm{k}$ and $\mathrm{I}$ are the Miller indices of the plane and a and $\mathrm{c}$ are the lattice parameter of the body-centred-tetragonal (BCT) $\mathrm{Al}_{2} \mathrm{Cu}$ unit cell. Hence it can be concluded that precipitates in this study do not contain significant thermally induced residual stresses that could influence the behaviour of different planes in the aluminium matrix.

Table 3: Spacing of selected $\theta$-phase planes, averaged from both detectors

\begin{tabular}{lllll}
\hline phase & $\{202\}_{\theta}$ & $\{310\}_{\theta}$ & $\{112\}_{\theta}$ & $\{220\}_{\theta}$ \\
\hline Measured by present authors & $1.8997 \pm 9.4 \mathrm{e}-4 \AA$ & $1.9181 \pm 2.8 \mathrm{e}-4 \AA$ & $2.1193 \pm 9.4 \mathrm{e}-4 \AA$ & $2.1445 \pm 7.5 \mathrm{e}-4 \AA$ \\
from Bradley and Jones [46] & $1.8997 \AA$ & $1.9182 \AA$ & $2.1190 \AA$ & $2.1447 \AA$
\end{tabular}

Figure 8 (a) and (b) show the calculated residual stress profiles after vertical inter-pass rolling and side rolling respectively in the three principal directions, of which the longitudinal ones are responsible for the out-of-plane distortion $\mathrm{D}$ of the substrate. In the clamped condition, the as-deposited longitudinal residual stresses are near the as-deposited flow strength of $130 \mathrm{MPa}$ [38] and virtually constant along the wall height (z-direction). After unclamping, which allows the sample to distort, the longitudinal stress decreases linearly in build direction, becoming even compressive at the top. Similar results have been obtained for steel and Ti-6AI-4V WAAM [12][14], [17]. In the vertical inter-pass rolled samples shown in Figure 8 (a), the $28 \mathrm{kN}$ profile is fairly constant up to $14 \mathrm{~mm}$ above the substrate at approximately $60 \mathrm{MPa}$. The $42 \mathrm{kN}$ profile is similar, but shows an increase between $10 \mathrm{~mm}$ and $14 \mathrm{~mm}$ up to $100 \mathrm{MPa}$. The top $7 \mathrm{~mm}$ of both show compressive stress, induced by the last rolling step. It should be noted that the distortion in both samples were identical. The $14 \mathrm{kN}$ profile however, which is the one that contained only a little residual distortion, also shows the compressive region at the top. But its entire profile has a linear 
trend with values almost identical to the unrolled profile as opposed to the other two inter-pass rolled profiles.
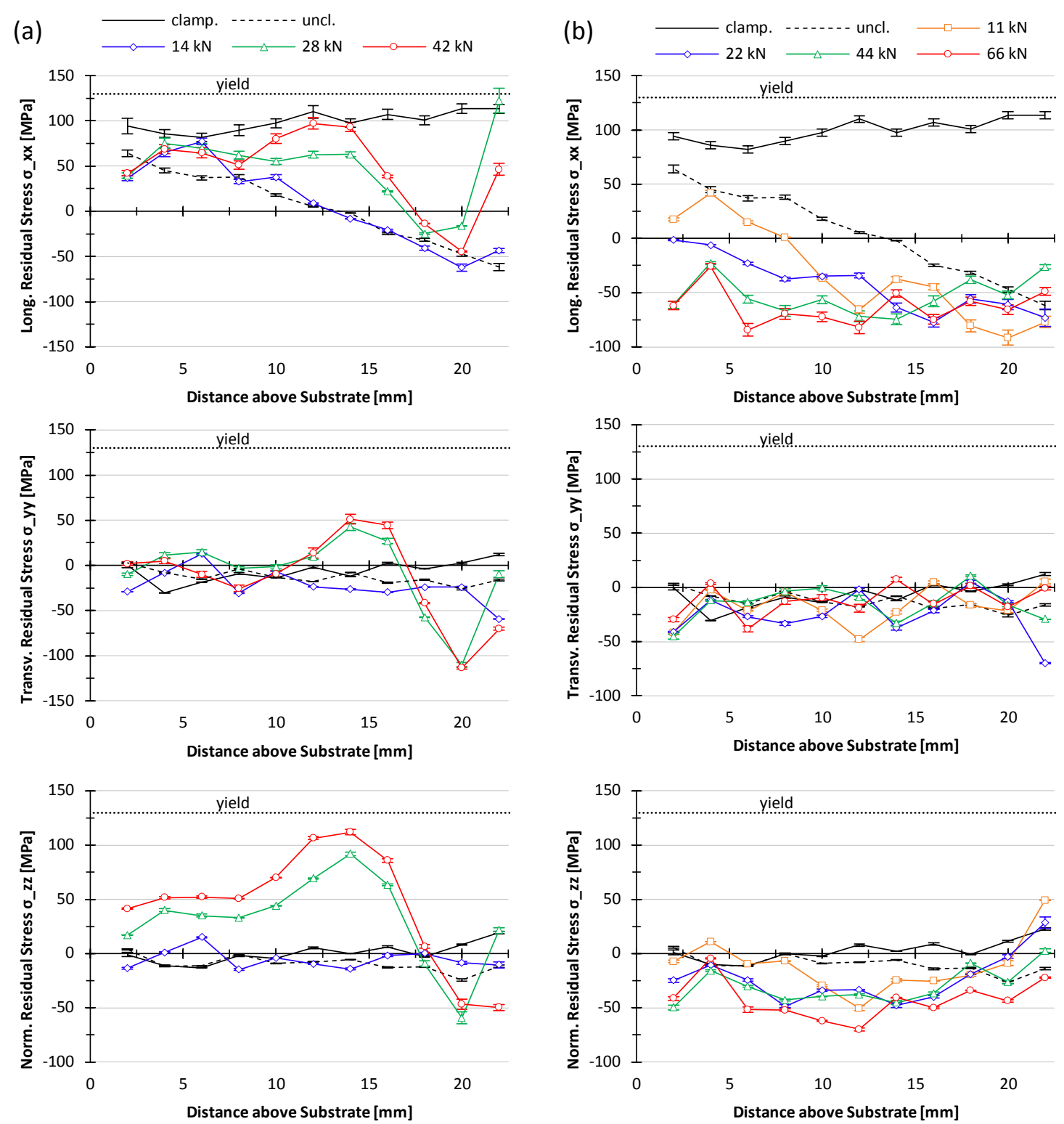

Figure 8: Principal residual stress modification after (a) inter-pass rolling and (b) side rolling, compared to the materials yield strength of $130 \mathrm{MPa}$ [38].

The profiles of the side-rolled samples are plotted in Figure 8 (b). Bearing in mind that all siderolling loads used during this study inverted the distortion, and hence the rolling loads were too high, all stress profiles except one appear to be compressive and constant along the z-axis at about -50 MPa. The $11 \mathrm{kN}$ load had a slightly higher stress near the substrate and was similar in shape and magnitude to the control sample. In terms of the residual stresses in the transverse and normal directions, the unrolled and the side-rolled samples, as well as the $14 \mathrm{kN}$ inter-pass rolled sample are negligible or slightly compressive. The transverse direction of the $28 \mathrm{kN}$ and $42 \mathrm{kN}$ inter-pass profiles are negligible up to $10 \mathrm{~mm}$ above the substrate. Between $10 \mathrm{~mm}$ and the top of the wall both show a tension-compression pattern similar to the longitudinal direction, 
indicating a three-dimensional stress state. The normal direction of both high inter-pass rolling loads appears similar to the transverse direction, but altered by approximately $+50 \mathrm{MPa}$.

\section{Discussion}

\subsection{Residual Stress \& Distortion}

The magnitude of the longitudinal tensile residual stress after deposition while the sample remained clamped was near the yield strength of as-deposited 2319 as reported by Gu et al. [38]. This suggest that the material developed residual stresses during cooling that exceeded the flow stress at respective temperatures, which was observed before during the deposition of steel .[12], [13]. Due to the low as-deposited strength of $130 \mathrm{MPa}$ [38] and the inferential low elastic strain $\left(\propto \sigma_{y} / E\right)$ considering the Young's modulus $E=73.1 \mathrm{GPa}$ [45], the level of distortion is relatively low compared to other metals after unclamping [12], [14], [48], [49]. Mitigating distortion in additively manufactured aluminium alloys (for example with rolling) is therefore easier compared with other metals.

\subsubsection{Vertical Inter-Pass Rolling}

Indeed a load of $28 \mathrm{kN}$ was sufficient to virtually eliminate distortion. To put this into context, the elimination of distortion with steel and Ti-6Al-4V deposits has not been possible at all in this way and caused the structure to fracture instead [12], [33], [50]. The residual stresses plots in Figure 8 indicate that rolling produced compressive stresses in the longitudinal direction near the top of the wall. Underneath and at the top surfaces tensile stresses were produced. As explained in Colegrove et al. [12], the final residual stress state is a consequence of the competition between the emergence of the tensile residual stresses during deposition and the field size of the compressive stresses produced by rolling. The significant tensile stresses underneath the compressive rolled region would suggest that the influence of the deposition process is greater (Figure 8). Nevertheless their magnitude is relatively low due to the low yield strength in the asdeposited state. The top-most stress gauge volume seems to be barely affected by the last rolling step, which can be attributed to friction between roller and wall that prevents plastic flow in the top of the wall in the interface with the roller [51].

The reasons why vertical inter-pass rolling is successful in eliminating distortion of aluminium deposits (unlike steel and titanium) could be due to several reasons. As stated above, the distortion with aluminium is relatively low, therefore less strain is required for its removal in the first place. Another beneficial property is the great ductility of deposited 2319 alloy, combined with a significantly larger ultimate strength compared to its yield value (130 MPa / $260 \mathrm{MPa}$ ) [38]. The material can tolerate large plastic deformation transverse to the wall direction without failing, which may facilitate plastic straining in the longitudinal direction. In addition, plastic 
anisotropy and the Bauschinger effect may result in a lower yield strength in the longitudinal direction after severe plastic work transverse to the wall length [52]. This would also promote yielding in the longitudinal direction, facilitating the reduction in distortion. Finally, the low yield strength, and large ductility enables a significant amount of material flow at the interface with the roller with a relatively modest load which promotes strain underneath the roller at a high depth.

The residual stress plots in Figure 8 illustrate how high loads generated significant compressive stress underneath the rolled region, while the lower load (14 kN) had virtually no impact on the residual stress profile. Cozzolino et al. [51] in their investigations on rolling of welds demonstrated that increasing rolling loads caused the peak compressive residual stress to increase at a greater distance from the rolled surface. Therefore the cold worked region with the small load in the present study will be relatively close to the top of the wall, so it can be relieved by the process heat from the subsequent layer. This would explain the almost identical stress profile for the small load compared to the as-deposited wall after unclamping.

In all other measurements of WAAM samples [12], [16], [33], [48], [49] the stresses in the transverse and normal directions were relatively small in thin walls - hence a plane stress condition can be assumed. However vertical rolling widened the wall significantly (Table 2), precluding the plane-stress assumption and enabling the wall to balance stresses through thickness. In this study, high vertical rolling loads produced compressive stress in the transverse direction with a peak at around $3 \mathrm{~mm}$ to $4 \mathrm{~mm}$ below the top of the wall. This compressive stress seems to be balanced by the material below with a tensile peak at $8 \mathrm{~mm}$ to $9 \mathrm{~mm}$ below the top of the wall. The not insignificant stresses in this direction are highly unusual, although the wall width for the $42 \mathrm{kN}$ rolled specimen may facilitate the generation of stresses in this direction. Even more noteworthy was the strong tensile stresses at the same location in the normal direction, with a small compressive region near the top of the wall. The only explanation is that the normal tensile stress at the centre line of the wall is balanced by compressive stress near the wall's surface. Unfortunately stresses at the surface were not measured within this study since the stress gradient across the thickness is normally small. Therefore it would appear that a state of hydrostatic tension exists within the centre of the wall, $8-9 \mathrm{~mm}$ from the surface.

\subsubsection{Side-Rolling}

All the loads used for the side rolling investigation inverted the distortion. Hence the $11 \mathrm{kN}$ rolling load applied to the $20 \mathrm{~mm}$ rolling width using a $150 \mathrm{~mm}$ roller is still too high to eliminate distortion in the $6 \mathrm{~mm}$ thick aluminium wall manufactured with WAAM. Compared to a Ti-6Al-4V wall with the same dimensions, where $130 \mathrm{kN}$ produced a zero-distortion part, [14] $11 \mathrm{kN}$ is very 
low. The reason why such a low load is sufficient, is as stated above the small residual distortion and small nominal strain required to balance the stress produced by deposition. A second reason is that the aluminium wall already contains longitudinal tensile stresses near the yield value so straining the material by rolling instantly deforms the wall plastically. This is different to titanium for example, where the wall needs to be rolled with a sufficiently high load to first yield and then plastically deform the material before the tensile residual stress can be effectively redistributed [14]. The side surface of the aluminium wall is rather uneven, which is why the roller did not touch the wall surface over the entire roller width when using a rolling load as low as $11 \mathrm{kN}$ (Figure $4(e)$ ). This caused non-uniform straining along the wall height and length, which is why further decreasing the load was not considered reasonable. Machining prior to rolling (down to the effective wall width for example) could overcome the issue by providing a constant contact pressure during the flat roller contact. It is furthermore expected that walls much wider than those used in the present paper can successfully be side rolled for distortion control. However, the occurrence of through thickness stress variations after side rolling of thicker sections should be expected.

In general, side rolling is more effective than vertical inter-pass rolling in respect to residual stress and distortion reduction for a given load. Furthermore, side rolling is applied only once to the final part instead of after each layer, so the impact on productivity is considerably less. However side cannot be easily applied to complex shapes that involve close features and intersections which cannot be accessed easily [14]. The results however encourage the design of a pinch-rolling device with potentially smaller roller diameter.

\subsection{Hardness}

The increased average hardness of the side-rolled samples with increasing rolling load (Figure $6(b)$ is due to work hardening. The random increase across the wall height is due to variations in wall width which concentrates the strain under the roller contact.

The average hardness within the bulk material of the $14 \mathrm{kN}$ vertical inter-pass rolled sample is $83 \mathrm{HV}$ and is similar to the unrolled control sample (Figure 6 (a). As stated above, this load had virtually no effect on the residual stress profile because the deformation was likely to be concentrated near the top surface. Therefore any work hardening caused by this load will be eliminated by the heat from the subsequent layer. The hardness of the $28 \mathrm{kN}$ and $42 \mathrm{kN}$ interpass rolled walls was significantly higher (Figure 6a) and are similar to the values reported by Gu et al. [38]. This might be attributed to work hardening, when the deformation reaches to a greater depth than the thermal field annealing the material. However it is also credible that an improved microstructure contributes to the increase in hardness/strength. The fact that the stress free 
lattices of the inter-pass rolled specimens for both higher loads are significantly larger than the unrolled one suggests the following explanation: It is known that the aluminium lattice parameter $a$ typically decreases by $0.0048 \AA\left(\varepsilon=-1185 \times 10^{-6}\right)$ per atomic percent copper added to the alloy [47]. The larger stress free lattice parameter $a_{0}$ of the inter-pass rolled samples bears the evidence for a decreased solutionised copper content in the aluminium matrix. In conclusion, the copper must have formed precipitates that could also contribute to an increase in strength, depending on their size. Finally, the even further increase in hardness in the top of each vertical inter-pass rolled specimen compared to the bulk material is caused by work hardening only.

Figure 9 (a) shows a relationship between the measured hardness of the bulk material and the average lattice size in the same region. The aluminium walls that contain less copper in the matrix are proportionally harder than those with a higher content, because the copper could have formed strengthening precipitates This is possible, as rolling can promote aging, by providing more dislocations and grain boundaries. These act as segregation sites, where $\mathrm{Al}_{x} \mathrm{Cu}_{\mathrm{y}}$ can precipitate. The promoted and inherent aging, which is triggered by the process heat of the subsequent layer after rolling, presumably increases the strength of inter-pass rolled alloy. Gu et al. [38] reported on the increased amount and more randomly distributed copper-aluminium precipitates in the rolled samples, compared to the as-deposited state. The SEM images in Figure 9 (b) and (c) taken from Gu et al. [38] show the $\theta$ phase precipitates on grain boundaries and dendrites and how the number of grains and grain boundaries grew when inter-pass rolling was implemented during the build. However, it important to note that it is not the morphology of this $\theta$ phase that is responsible for the strength increase in this alloy, but instead the much smaller $\theta^{\prime \prime}$ precipitates, which are semi-coherent with the aluminium matrix and cannot be resolved with neutron diffraction.

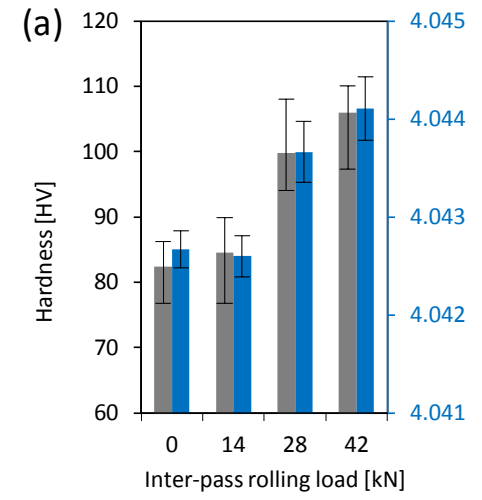

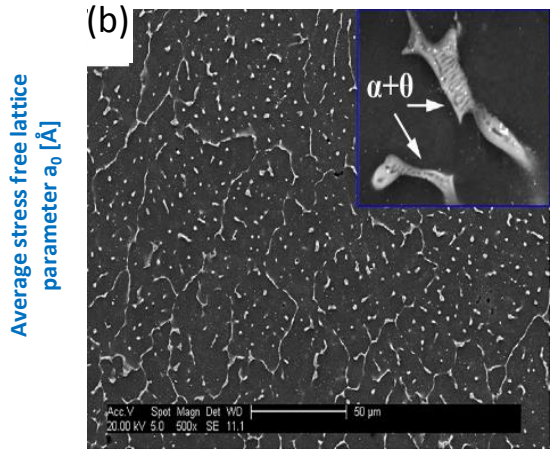

As deposited $(0 \mathrm{kN})$

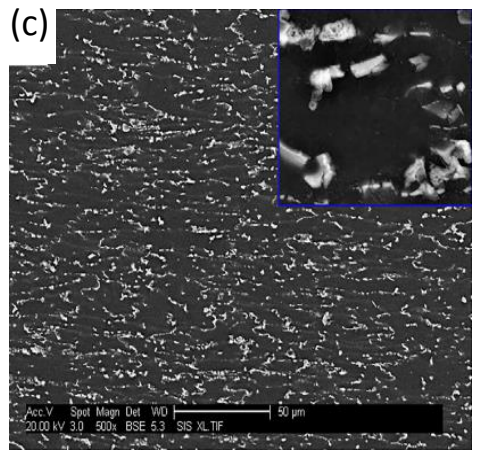

Inter-pass rolled $(45 \mathrm{kN})$

Figure 9: (a) Correlation between hardness and increased lattice parameter versus applied inter-pass rolling load; SEM images showing the morphology of $\mathrm{Al} 2 \mathrm{Cu} \theta$ phase in the (b) as-deposited wall and (c) the inter-pass rolled wall (c) [38] 


\section{Conclusion}

In this study the effect of vertical inter-pass rolling and post-deposition side rolling on 2319 aluminium walls produced by Wire + Arc Additive Manufacture have been investigated. It was demonstrated that:

1. The longitudinal residual stress without cold rolling can be as high as the material's flow strength in the as-deposited condition. The distortion in asymmetrically built parts can be significant, but is generally lower than other metals due to the low yield strength in the as-deposited state for this aluminium alloy.

2. Vertical inter-pass rolling modifies the residual stress in aluminium WAAM and it can eliminate the distortion unlike previous investigations on Ti-6Al-4V and mild steel walls.

3. Vertical inter-pass rolling work hardens the material and promotes dissolution of copper from the matrix. It is possible that this has facilitated natural aging of the material, which in combination with the work hardening provides improved yield and tensile strengths.

4. Post-deposition side-rolling is very effective for controlling residual stresses and distortion in aluminium parts manufactured with WAAM and it increases the hardness by work hardening.

\section{Acknowledgement}

The authors would like to give their gratitude to Flemming Nielsen from Cranfield University and Peter Ledgard from The Open University in Milton Keynes for technical support during the production of the specimen. The authors also wish to acknowledge the financial support of the European AMAZE project (no 313781) and the industrial partners of the WAAMMat programme, who funded the work presented in this paper. The neutron diffraction experiments on the ENGIN-X beam line were granted by the STFC in Didcot under proposal RB1620099.

\section{References}

[1] S. W. Williams, F. Martina, a. C. Addison, J. Ding, G. Pardal, and P. Colegrove, "Wire+Arc Additive Manufacturing," Mater. Sci. Technol., vol. 32, no. 7, pp. 641-647, 2015.

[2] P. Kazanas, P. Deherkar, P. Almeida, H. Lockett, and S. Williams, "Fabrication of geometrical features using wire and arc additive manufacture," Proc. Inst. Mech. Eng. Part B J. Eng. Manuf., vol. 226, pp. 1042-1051, 2012.

[3] P. M. Sequeira Almeida and S. Williams, "Innovative process model of Ti-6Al-4V additive layer manufacturing using cold metal transfer (CMT)," 2010

[4] F. Martina, J. Mehnen, S. W. Williams, P. Colegrove, and F. Wang, "Investigation of the benefits of plasma 
deposition for the additive layer manufacture of Ti-6Al-4V," J. Mater. Process. Technol., vol. 212, pp. 13771386, 2012.

[5] D. D. Gu, W. Meiners, K. Wissenbach, and R. Poprawe, "Laser additive manufacturing of metallic components: materials, processes and mechanisms," Int. Mater. Rev., vol. 57, no. 3, pp. 133-164, 2012.

[6] D. Ding, Z. Pan, D. Cuiuri, and H. Li, "Wire-feed additive manufacturing of metal components: technologies, developments and future interests," Int. J. Adv. Manuf. Technol., vol. 81, no. 1-4, pp. 465-481, 2015.

[7] C. Qiu, G. a. Ravi, C. Dance, A. Ranson, S. Dilworth, and M. M. Attallah, "Fabrication of large Ti-6Al-4V structures by direct laser deposition," J. Alloys Compd., vol. 629, pp. 351-361, 2015.

[8] A. A. Antonysamy, J. Meyer, and P. B. Prangnell, "Effect of build geometry on the $\beta$-grain structure and texture in additive manufacture of Ti-6AI-4V by selective electron beam melting," vol. 84, pp. 153-168, 2013.

[9] J. Mehnen, J. Ding, H. Lockett, and P. Kazanas, “Design study for wire and arc additive manufacture Jörn Mehnen * and Jialuo Ding Panos Kazanas," Int. J. Prod. Dev., vol. 19, no. 1-3, pp. 2-20, 2014.

[10] C. M. A. Silva, I. M. F. Braganca, A. Cabrita, L. Quintino, and P. A. F. Martins, "Formability of a wire arc deposited aluminium alloy," Brazilian Soc. Mech. Sci. Eng., vol. 39, pp. 4059-4068, 2017.

[11] H. E. Coules, L. D. Cozzolino, P. Colegrove, S. Ganguly, S. W. Wen, and T. Pirling, "Neutron Diffraction Analysis of Complete Residual Stress Tensors in Conventional and Rolled Gas Metal Arc Welds," Exp. Mech., vol. 53, pp. 195-204, 2013.

[12] P. A. Colegrove, H. E. Coules, J. Fairman, F. Martina, T. Kashoob, H. Mamash, and L. D. Cozzolino, "Microstructure and residual stress improvement in wire and arc additively manufactured parts through highpressure rolling," J. Mater. Process. Technol., vol. 213, pp. 1782-1791, 2013.

[13] J. Ding, P. Colegrove, J. Mehnen, S. Ganguly, P. M. S. Almeida, F. Wang, and S. Williams, "Thermo-mechanical analysis of Wire and Arc Additive Layer Manufacturing process on large multi-layer parts," Comput. Mater. Sci., vol. 50, no. 12, pp. 3315-3322, 2011.

[14] J. R. Hönnige, S. Williams, M. J. Roy, P. Colegrove, and S. Ganguly, "Residual Stress Characterization and Control in the Additive Manufacture of Large Scale Metal Structures," in 10th International Conference on Residual Stresses, 2016

[15] J. R. Hönnige, P. A. Colegrove, B. Ahmad, M. E. Fitzpatrick, S. Ganguly, T. L. Lee, and S. W. Williams, "Residual stress and texture control in Ti-6Al-4V wire + arc additively manufactured intersections by stress relief and rolling a ) b )," Mater. Des., vol. 150, pp. 193-205, 2018.

[16] J. Ding, P. Colegrove, J. Mehnen, S. Williams, F. Wang, and P. S. Almeida, "A computationally efficient finite element model of wire and arc additive manufacture," Int. J. Adv. Manuf. Technol., vol. 70, pp. 227-236, 2014.

[17] T. Mukherjee, W. Zhang, and T. Debroy, "An improved prediction of residual stresses and distortion in additive manufacturing," Comput. Mater. Sci., vol. 126, pp. 360-372, 2017.

[18] R. Sun, L. Li, Y. Zhu, W. Guo, P. Peng, and B. Cong, "Microstructure, residual stress and tensile properties control of wire- arc additive manufactured 2319 aluminum alloy with laser shock peening," J. Alloys Compd., vol. 747, pp. 255-265, 2018.

[19] C. A. Brice and W. H. Hofmeister, "Determination of Bulk Residual Stresses in Electron Beam Additive- 
Manufactured Aluminum," Miner. Met. Mater. Soc., vol. 44, no. November, pp. 5147-5153, 2013.

[20] H. E. Coules, "Contemporary approaches to reducing weld-induced residual stress," Mater. Sci. Technol., vol. 29 , no. 1, 2012.

[21] W. T. Han, F. R. Wan, G. Li, C. L. Dong, and J. H. Tong, "Effect of trailing heat sink on residual stresses and welding distortion in friction stir welding Al sheets," vol. 16, no. 5, pp. 453-458, 2011.

[22] L. Parry, I. A. Ashcroft, and R. D. Wildman, "Understanding the effect of laser scan strategy on residual stress in selective laser melting through thermo-mechanical simulation," Addit. Manuf., vol. 12, pp. 1-15, 2016.

[23] G. Vastola, G. Zhang, Q. X. Pei, and Y.-W. Zhang, "Controlling of residual stress in additive manufacturing of Ti6Al4V by finite element modeling," Addit. Manuf., 2016.

[24] F. Lienert, J. Hoffmeister, and V. Schulze, "Residual Stress Depth Distribution after Piezo Peening of Quenched and Tempered AISI 4140," Mater. Sci. Forum, vol. 768-769, pp. 526-533, 2014.

[25] X. Cheng, J. W. Fisher, H. J. Prask, T. Gnäupel-Herold, B. T. Yen, and S. Roy, "Residual stress modification by post-weld treatment and its beneficial effect on fatigue strength of welded structures," Int. J. Fatigue, vol. 25, pp. 1259-1269, 2003.

[26] P. Staron, M. Koçak, S. Williams, and a Wescott, "Residual stress in friction stir-welded Al sheets," Phys. B Condens. Matter, vol. 350, no. 1-3, pp. E491-E493, 2004.

[27] D. A. Price, S. W. Williams, A. Wescott, C. J. C. Harrison, A. Rezai, A. Steuwer, M. Peel, P. Staron, and M. Koçak, "Distortion control in welding by mechanical tensioning," Sci. Technol. Weld. Join., vol. 12, no. 7, pp. 620-633, 2007.

[28] V. I. Kurkin, S. A., Anufriev, "Preventing distortion of welded thin-walled members of AMg6 and 1201 aluminum alloys by rolling the weld with a roller behind the welding arc," Sverochnoe Proizv., vol. 31, no. 10, pp. 52-55, 1984.

[29] J. Altenkirch, A. Steuwer, P. J. Withers, S. W. Williams, M. Poad, and S. W. Wen, "Residual stress engineering in friction stir welds by roller tensioning," Sci. Technol. Weld. Join., vol. 14, no. 2, pp. 185-192, 2009.

[30] D. F. O. Braga, H. E. Coules, T. Pirling, V. Richter-Trummer, P. Colegrove, and P. M. S. T. De Castro, “Assessment of residual stress of welded structural steel plates with or without post weld rolling using the contour method and neutron diffraction," J. Mater. Process. Technol., vol. 213, no. 12, pp. 2323-2328, 2013.

[31] H. E. Coules, P. Colegrove, L. D. Cozzolino, S. W. Wen, S. Ganguly, and T. Pirling, "Effect of high pressure rolling on weld-induced residual stresses," Sci. Technol. Weld. Join., vol. 17, no. 5, pp. 394-401, 2012.

[32] F. Martina, M. Roy, P. Colegrove, and S. Williams, "Residual Stress Reduction in High Pressure Interpass Rolled Wire + Arc Additive Manufacturing Ti-6Al-4V components," in 25th International Solid Freeform Fabrication, 2014, pp. 89-94

[33] P. A. Colegrove, F. Martina, M. J. Roy, B. Szost, S. Terzi, S. W. Williams, P. J. Withers, and D. Jarvis, "High pressure interpass rolling of Wire + Arc Additively Manufactured titanium components," Adv. Mater. Res., vol. 996, pp. 694-700, 2014.

[34] Y. Xie, H. Zhang, and F. Zhou, "Improvement in geometrical accuracy and mechanical property for arc-based additive manufacturing using metamorphic rolling mechanism," J. Manuf. Sci. Eng., vol. 138, no. November, 
pp. 1-8, 2015.

[35] F. Wang, S. Williams, P. Colegrove, and A. A. Antonysamy, "Microstructure and mechanical properties of wire and arc additive manufactured Ti-6Al-4V," Metall. Mater. Trans. A Phys. Metall. Mater. Sci., vol. 44, pp. 968977, 2012.

[36] M. F. Ashby and D. R. H. Jones, Engineering materials 2 an introduction to microstructures, processing and design, 3rd ed. Cambridge: Oxford : Elsevier Butterworth-Heinemann, 2006.

S. Kou, WELDING METALLURGY, 2nd Editio. 2003.

[38] J. Gu, J. Ding, S. W. Williams, H. Gu, P. Ma, and Y. Zhai, "The strengthening effect of inter-layer cold working and post-deposition heat treatment on the additively manufactured Al-6.3Cu alloy," Mater. Sci. Eng. A, vol. 651, pp. 18-26, 2016.

[39] J. Gu, J. Ding, S. W. Williams, H. Gu, P. Ma, and Y. Zhai, "The effect of inter-layer cold working and postdeposition heat treatment on porosity in additively manufactured aluminum alloys," J. Mater. Process. Technol., vol. 230, pp. 26-34, 2016.

[40] B. Cong, J. Ding, and S. Williams, "Effect of arc mode in cold metal transfer process on porosity of additively manufactured Al-6.3\%Cu alloy," Int. J. Adv. Manuf. Technol., vol. 76, no. 9-12, pp. 1593-1606, 2014.

[41] J. Donoghue, A. A. Antonysamy, F. Martina, P. A. Colegrove, S. W. Williams, and P. B. Prangnell, "The effectiveness of combining rolling deformation with Wire-Arc Additive Manufacture on $\beta$-grain refinement and texture modification in Ti-6Al-4V," Mater. Charact., vol. 114, pp. 103-114, 2016.

[42] P. A. Colegrove, J. Donoghue, F. Martina, J. Gu, P. Prangnell, and J. Hönnige, "Application of bulk deformation methods for microstructural and material property improvement and residual stress and distortion control in additively manufactured components," Scr. Mater., vol. 2, 2016.

[43] J. R. Santisteban, M. R. Daymond, J. A. James, and L. Edwards, "ENGIN-X: A third-generation neutron strain scanner," J. Appl. Crystallogr., vol. 39, no. 6, pp. 812-825, 2006.

[44] G. S. Pawley, “Unit-cell refinement from powder diffraction scans," J. Appl. Crystallogr., vol. 14, p. 357, 1981.

[45] J. M. Holt, H. Mindlin, and C. Y. Ho, Structural alloys handbook. Lafayette (IN): CINDAS/Purdue University, 1994.

[46] A. J. Bradley and P. Jones, "An X-ray investigation of the copper-aluminium alloys," J. Inst. Met. London, vol. 51, p. 131, 1933.

[47] J. P. Lokker, N. M. van der Pers, A. H. Verbruggen, G. C. Janssen, J. F. Jongste, and S. Radelaar, "Localized stress near and the thermal expansion of Al2Cu precipitates in an Al thin film matrix," J. Appl. Phys., vol. 87, no. 2, p. $682,2000$.

[48] B. A. Szost, S. Terzi, F. Martina, D. Boisselier, A. Prytuliak, T. Pirling, M. Hofmann, and D. J. Jarvis, "A comparative study of additive manufacturing techniques: Residual stress and microstructural analysis of CLAD and WAAM printed Ti-6AI-4V components," Mater. Des., vol. 89, pp. 559-567, 2016.

[49] F. Martina, M. J. Roy, B. A. Szost, S. Terzi, P. A. Colegrove, S. W. Williams, P. J. Withers, J. Meyer, and M. Hofmann, "Residual stress of as-deposited and rolled wire+arc additive manufacturing Ti-6Al-4V components," Mater. Sci. Technol., vol. 0836, no. April, 2016.

[50] F. Martina, P. A. Colegrove, S. W. Williams, and J. Meyer, "Microstructure of Interpass Rolled Wire + Arc 
Additive Manufacturing Ti-6Al-4V Components," Metall. Mater. Trans. A Phys. Metall. Mater. Sci., vol. 46, no. 12, pp. 6103-6118, 2015.

[51] L. D. Cozzolino, H. E. Coules, P. A. Colegrove, and S. Wen, "Investigation of post-weld rolling methods to reduce residual stress and distortion," J. Mater. Process. Technol., vol. 247, pp. 243-256, 2017.

[52] Chakrabarty and Jagabandhu, Applied Plasticity, Second Edition, 2nd ed. Springer US, 2010. 
2018-06-25

Control of residual stress and distortion in aluminium wire + arc additive manufacture with rolling

Honnige, Jan

Elsevier

Hönnige J, Colegrove P, Ganguly S, et al.,Control of residual stress and distortion in aluminium wire + arc additive manufacture with rolling. Additive Manufacturing, Volume 22, August 2018, pp. 775-783

https://doi.org/10.1016/j.addma.2018.06.015

Downloaded from Cranfield Library Services E-Repository 